\title{
An assessment of urbanization sustainability in China between 1990 and 2015 using land use efficiency indicators
}

\author{
Huiping Jiang $\mathbb{C}^{1,5}$, Zhongchang Sun $\mathbb{1}^{1,2,5}$, Huadong Guo $\mathbb{C}^{1 凶}$, Qihao Weng $\mathbb{C}^{3 凶}$, Wenjie Du ${ }^{1}$, Qiang Xing ${ }^{1}$ and Guoyin Cai ${ }^{4}$
}

The sustainability of China's rapid urbanization is of significance in the implementation of the 2030 Agenda for Sustainable Development. Here we integrated Earth observation and census data to estimate the relationship between land, population and economic domains of urbanization in 433 cities over 25 years using land use efficiency indicators. We find that the rise in ratio of land consumption to population growth rates (LCRPGR) was paralleled by a decline in ratio of economic growth to land consumption rates (EGRLCR). LCRPGR and EGRLCR of cities in Northeast China showed an abnormal and intense dynamics compared to other regions, suggesting that the northeastern region is more vulnerable to socioeconomic and environmental changes. The spatial expansion of superlarge cities in Central China may be unrestrained and should be the focus of strengthened regulations now and in the near future. The resource-dependent cities faced severe challenges for more effective actions of both economic transformation and population migration. Nonetheless, the gap of land use efficiency indicators between different income groups of the cities has been narrowed between 1990 and 2015, indicating that the evolution of urbanization in China is heading toward a more sustainable and coordinated process.

npj Urban Sustainability (2021)1:34; https://doi.org/10.1038/s42949-021-00032-y

\section{INTRODUCTION}

The 2030 Agenda for Sustainable Development (2030 Agenda) adopted by the United Nations (UN) General Assembly on 25 September 2015, presents a blueprint for all countries to achieve sustainable development over the next 15 years $^{1}$. Any successful path to achieving the 2030 Agenda will have to consider the development of sustainable urban and peri-urban environments ${ }^{2}$, as highlighted in six entry points for pursuing transformational change towards sustainable development ${ }^{3}$. The 2030 Agenda goal devoted to cities ('SDG 11: Make cities and human settlements inclusive, safe, resilient and sustainable'), lists many indicators requiring fine-scale local data. These indicators are categorized into three tiers according to the availability of assessment method and monitoring data. Although SDG 11.3.1-'ratio of land consumption rate to population growth rate (LCRPGR)'-is classified as a Tier II indicator (methods established but with poor data), the Earth observations allow to make up for data deficits using multisource data over a broader geographical area ${ }^{4,5}$.

Nowadays, multiple datasets are available to estimate urban spatial expansion, e.g., the Global Human Settlement Layer $(\mathrm{GHSL})^{6}$, Global Urban Land ${ }^{7}$, and Global Artificial Impervious Area $(\mathrm{GAIA})^{8}$. However, the literature related to SDG 11.3.1 still remains scarce, except for some local studies from China ${ }^{9}$, Portugal $^{10}$, and South Africa ${ }^{11}$, and a few global researches from $\mathrm{UN}^{12}$ and European Commission-Joint Research Centre ${ }^{13,14}$, because calculating the land consumption rate (LCR) needs conversion of built-up area ${ }^{15}$, and the estimation of population growth rate (PGR) requires spatial disaggregation of population data $^{16}$, both of which are challenging tasks.

The UN stressed that the goals and targets of the 2030 Agenda should balance the three indivisible dimensions of sustainable development, i.e., economic, social, and environmental, but the coordination between spatial expansion and economic growth has not yet been established under the assessment framework of SDG 11. Similarly to the 2030 Agenda, the urbanization process is also characterized by three integrated dimensions, namely spatial, demographic, and economic (land, population, and economic urbanization). Existing research on urbanization is mainly focused on the spatial expansion at local ${ }^{17}$, regional $^{18,19}$, national ${ }^{20-22}$, and global scales 23,24 . There are also many studies that investigate the correlation $^{25-28}$ and causality ${ }^{29-31}$ between land, population and economic urbanization. However, not enough attention has been paid to the relationship between these three dimensions in the context of rapid spatial expansion, since this has frequently been disproportionate to population and economic growth over the past several decades ${ }^{32}$. Moreover, many of these studies are only based on census data, in most cases, neglecting the spatial harmonization of different sources, and thus have limited spatiotemporal coverage and accuracy.

To address the lack of economic dimension, we proposed a supplementary indicator-ratio of economic growth rate to land consumption rate (EGRLCR) - which enables the quantitative estimation of coordination between LCR and economic growth rate (EGR). With LCRPGR and EGRLCR combined, we could uniformly define and determine the relationship between land, population and economic urbanization under the assessment framework of SDG 11. To address the discrepancy between different data sources, urban impervious surface was converted to built-up area to provide a measure of urban agglomeration area adopted by the World Urbanization Prospects ${ }^{33}$. In this way, we could allocate the exact population within the corresponding extent of built-up area defined in SDG 11.3.1, avoiding the spatial disaggregation of population data. Furthermore, the products of urban impervious surface could be consistently updated and

\footnotetext{
${ }^{1}$ Key Laboratory of Digital Earth Science, Aerospace Information Research Institute, Chinese Academy of Sciences, Beijing, China. ${ }^{2}$ Key Laboratory for Earth Observation of Hainan

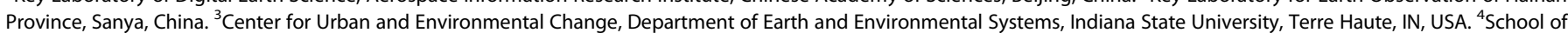
Geomatics and Urban Spatial Informatics, Beijing University of Civil Engineering and Architecture, Beijing, China. ${ }^{5}$ These authors contributed equally: Huiping Jiang,

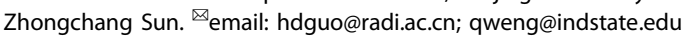


refined to ensure the quality of its spatiotemporal coverage and accuracy.

China has been experiencing an unprecedented pace of urbanization $^{34}$. The proportion of urban population in China is projected to reach $73 \%$ by 2030 , with $\sim 0.2$ billion people expected to be added to its urban areas ${ }^{33}$. During this historical process, all cities of various population sizes, with diverse income levels and in different socioeconomic zones are facing a quickened urbanization shock and showing a relatively significant heterogeneity of land use efficiency. An uneven and unbalanced urbanization is widespread among large, medium and small cities, as well as across the eastern, central and western regions ${ }^{25,26,35,36}$. Particularly, the sustainability of cities with monotonous industrial structure, such as resource-dependent cities, are subject to socioeconomic and environment changes. For those resourcedependent cities, whose economic development depends heavily on the exploitation and processing of natural resources, once the natural resources are exhausted, they would be confronted with enormous challenges for green transformation and sustainable development ${ }^{37}$. However, little is known to us as to how the evolution in terms of spatial, demographic, and economic dimensions and the differentiation at multiple aggregation scales had proceeded. To bridge this knowledge gap, it is necessary to conduct a multi-view analysis, with socioeconomic zones, population sizes, urban functions, and income levels included, to draw a big picture of urbanization in China.

Here we used multisource remote sensing imagery (Landsat and Sentinel time series data) to map urban impervious surface and then convert it to urban agglomeration area. After that, we calculated and tested the land use efficiency indicators by studying the spatiotemporal evolution of urbanization in China from 1990 to 2015 at 5-years intervals. Specifically, we integrated Earth observation and census data to explore a total of 433 cities with Mainland China, Hong Kong, Macao, and Taiwan included from various perspectives of socioeconomic zones, population sizes, urban functions, and income levels. Finally, we highlighted several important findings about spatiotemporal evolution of urbanization in China and elucidated the corresponding policy implications to promote sustainable development in urban areas.

\section{RESULTS}

\section{Overall trends in land use efficiency indicators}

The spatially explicit change in LCRPGR from 1990 to 2015 in China is shown in Fig. 1a-f. For the sake of comparison to other cities in international context, 433 county-level or higher cities with 300 thousand inhabitants or more adopted by the 2018 Revision of World Urbanization Prospects were sampled for this research. Here we calculated the averages by following the formulae of LCR, PGR, and LCRPGR based on aggregation of land area and number of persons for each year rather than used the statistical mean. As shown in Fig. 1g, the average of LCRPGR first dropped from 1.34 during $1990-1995$ to 0.85 during 1995-2000 and then increased to 1.82 during $2000-2005$ and to 1.59 during 2005-2010. The peak of average of LCRPGR (2.15) was observed during 2010-2015. However, the peak of average of LCR was observed during 1990-1995 and that of PGR was observed during 1995-2000. Here we found that LCR overwhelmed PGR for most cities in China since 2000 by comparing the distribution of LCR with that of PGR (for details, refer to Supplementary Fig. 2).

As shown in Fig. 1h, during the period of 1990-1995, the proportions of numbers of cities with $0<$ LCRPGR $\leq 1(47 \%), 1<$ LCRPGR $\leq 2$ (38\%), and LCRPGR $>2$ (14\%) occupied the top three positions. While during the period of 2010-2015, the top three positions were replaced by those with LCRPGR $>2(52 \%), 1<$ LCRPGR $\leq 2(30 \%)$, and $0<$ LCRPGR $\leq 1$ (18\%), respectively. In terms of dynamic change, the proportions of numbers of cities with
LCRPGR $>2$ experienced a significant upward trend while those with $\mathrm{LCRPGR} \leq 0$ remained below $1 \%$ throughout the whole process. It was worth noting that before 2000 , the proportion of numbers of cities with $1<\mathrm{LCRPGR} \leq 2$ first declined and then increased while those with $0<$ LCRPGR $\leq 1$ first increased and then declined, and after 2000, these two classes were slightly decreasing but relatively stable. Moreover, during the time period of 1990-2015, the proportions of numbers of cities with LCRPGR $>2,1<$ EGRLCR $\leq 2$, and $0<$ LCRPGR $\leq 1$ were 16,60 , and $24 \%$, respectively, (for details, refer to Supplementary Fig. 4-5).

The spatially explicit change of EGRLCR from 1990 to 2015 in China is shown in Fig. 2a-f. Due to the incompleteness of time series, we could only use a Gross Domestic Product (GDP) dataset at current prices of 313 cities in the time range of 1990-2015. Likewise, we calculated the averages by following the formulae of EGR, LCR, and EGRLCR based on aggregation of GDP and land area for each year rather than used the statistical mean. As shown in Fig. $2 \mathrm{~g}$, the average of EGRLCR firstly dropped from 2.81 during 1990-1995 to 1.77 during 1995-2000, and it then increased to 2.38 during 2000-2005 and 2.85 during 2005-2010. A trough in average of EGRLCR (1.69) was observed during 2010-2015. However, the trough in average of LCR was observed during the 2005-2010 and that of EGR was observed during 1995-2000. It was worth noting that the change of average of LCR remained relatively small compared to those of EGR and PGR, which both showed a general downward trend. By illustrating the scatter plot of LCR versus EGR for each period spanning 1990-2015, we could conclude that the coordination between land and economic urbanization showed significant improvement thanks to the speedup of spatial expansion coupled with slowdown of economic growth during 2010-2015 (for details, refer to Supplementary Fig. 3).

As shown in Fig. 2h, during the period of 1990-1995, the proportions of numbers of cities with EGRLCR $>4(46 \%), 2<$ $\mathrm{EGRLCR} \leq 4$ (44\%), and $1<\mathrm{EGRLCR} \leq 2$ (8\%) occupied the top three positions, while during the time period of 2010-2015, the top three positions were replaced by those with $1<\mathrm{EGRLCR} \leq 2$ (37\%), $2<\mathrm{EGRLCR} \leq 4$ (25\%), and $0<\mathrm{EGRLCR} \leq 1$ (19\%), respectively. In terms of dynamic change, the proportions of numbers of cities with EGRLCR $>4$ and $2<\mathrm{EGRLCR} \leq 4$ both experienced a general declining trend while those with $1<\mathrm{EGRLCR} \leq 2$ and $0<$ EGRLCR $\leq 1$ both expressed a general increasing trend. It is worth noting that the proportion of numbers of cities with $0<$ EGRLCR $\leq$ 1 showed a significant rise during the periods of 1995-2000 and 2010-2015. Moreover, during the period of 1990-2015, the proportion of numbers of cities with EGRLCR $>4,2<$ EGRLCR $\leq 4$, $1<\mathrm{EGRLCR} \leq 2$, and $0<\mathrm{EGRLCR} \leq 1$ were $12 \%, 66 \%, 21 \%$, and $1 \%$, respectively, (for details, refer to Supplementary Figs. 6-7).

\section{Urbanization sustainability of different regions and sizes}

Figure 3a-f shows the LCRPGR changes in various socioeconomic zones across 433 study cities of different urban sizes throughout the past 25 years. During the 1990-1995 period, the average of LCRPGR in the northeastern region (1.81) was the highest, followed by eastern region (1.38), western region (1.11), and central region (1.00). During the 2010-2015 period, the average of LCRPGR in all regions peaked with northeastern region reaching 3.70 , western region reaching 2.51 , eastern region reaching 1.99 , and the central region reaching 1.89 , respectively. In terms of dynamic change, the LCRPGR changes in the northeastern region faced an upsurge while those in other regions showed a stable and slight upward trend. Besides, we could see that the averages of LCRPGR in the northeastern region remained above those across the entire country throughout the whole evolution and the averages of LCRPGR of superlarge cities in the central region far exceed those of all cities in China since 2000. It was not difficult to determine that cities of different urban sizes in Northeast China 

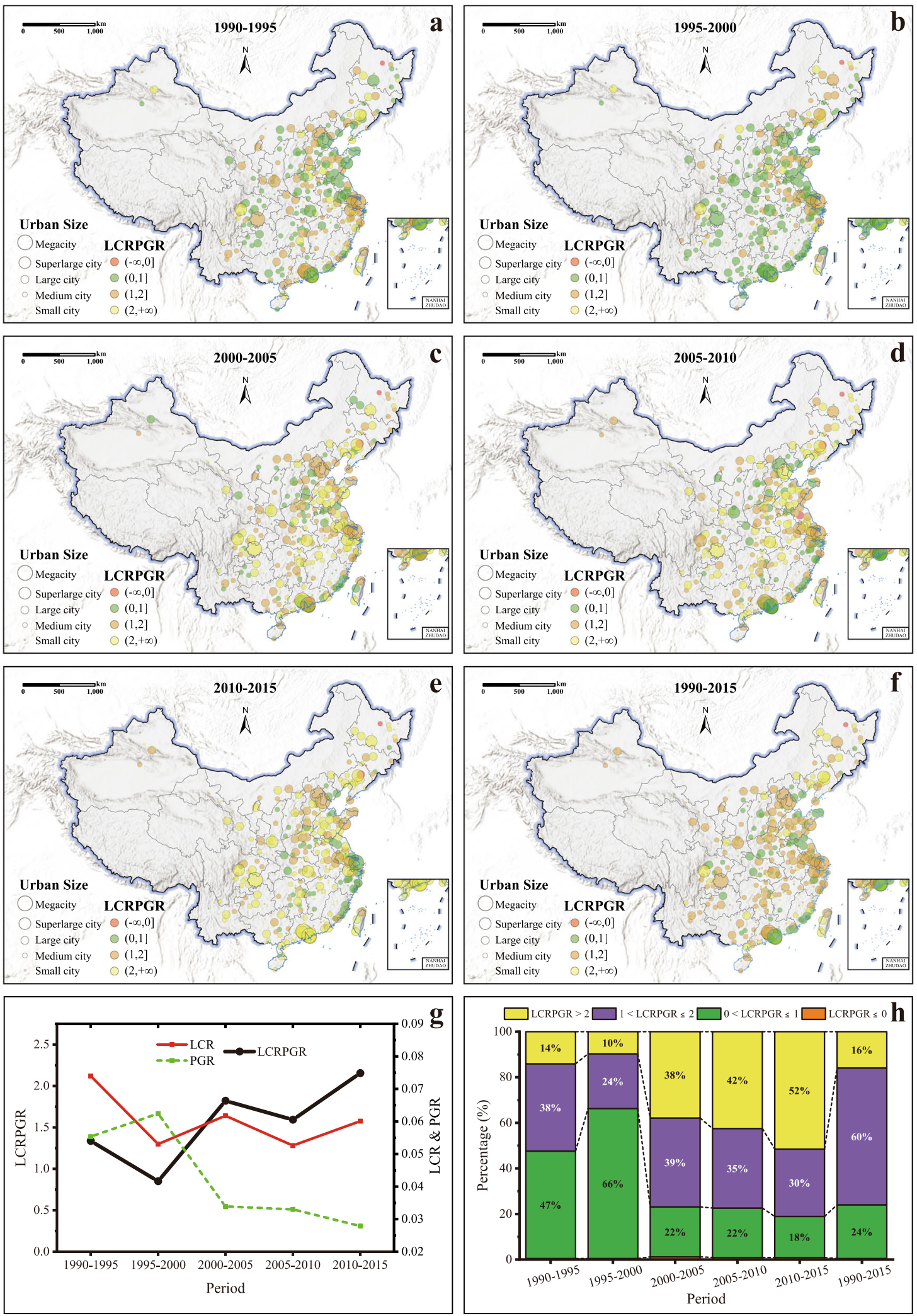

Fig. 1 Changes in ratio of land consumption rate to population growth rate (LCRPGR) of $\mathbf{4 3 3}$ cities in China. a Changes for period 1990-1995. b Changes for period 1995-2000. c Changes for period 2000-2005. d Changes for period 2005-2010. e Changes for period 2010-2015. f Changes for period 1990-2015. g Changes of averages of land consumption rate (LCR), population growth rate (PGR) and LCRPGR for sample cities spanning 1990-2015. h Proportions of numbers of cities grouped by different LCRPGR classes spanning 1990 to 2015. The relief background of map is an ArcGIS online basemap (World Hillshade (WGS84)) obtained from the ArcMap software by Esri (http://goto.arcgisonline.com/maps/Elevation/World_Hillshade). 

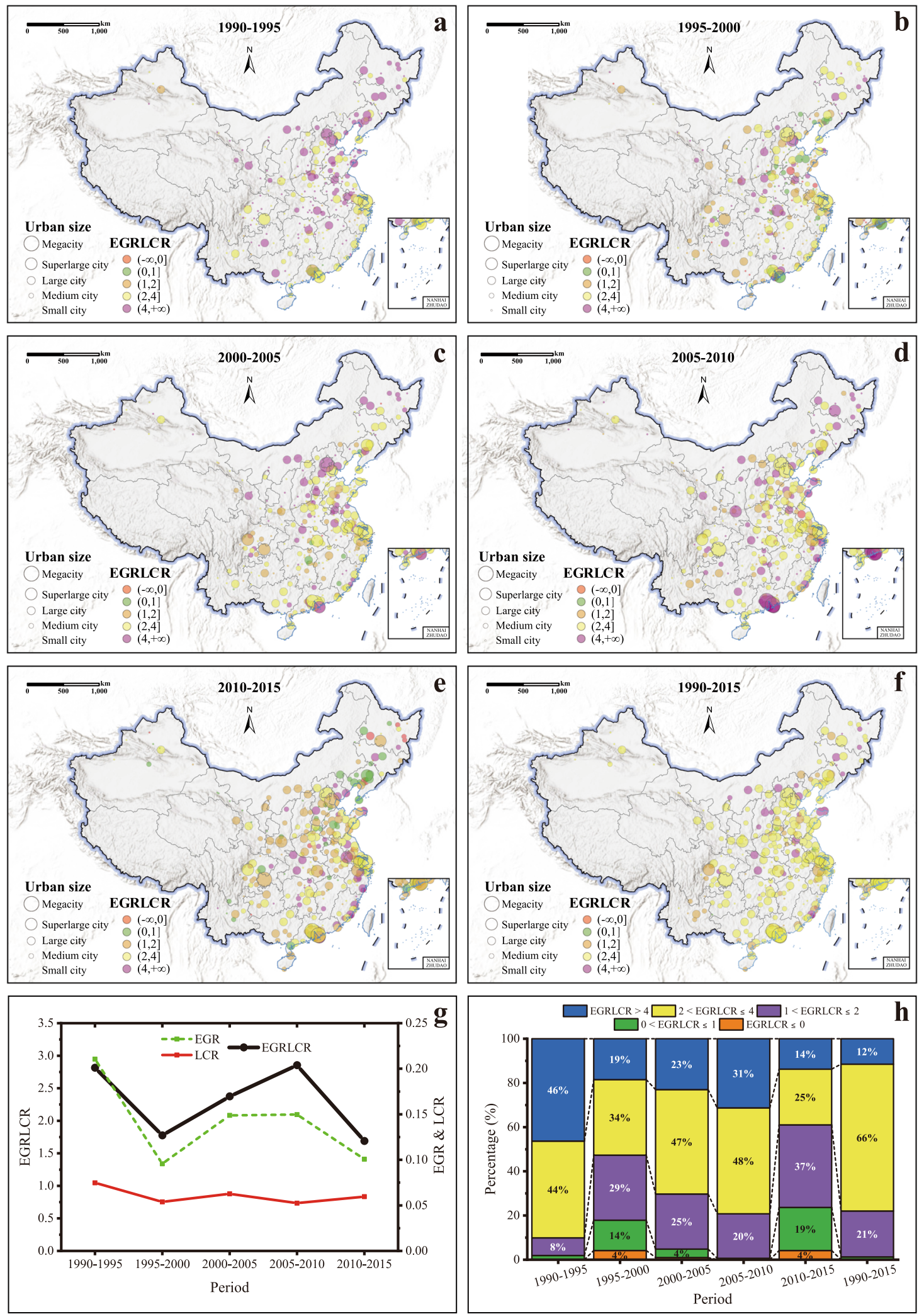

Fig. 2 Changes in ratio of economic growth rate to land consumption rate (EGRLCR) of $\mathbf{3 1 3}$ cities in China. a Changes for period 1990-1995. b Changes for period 1995-2000. c Changes for period 2000-2005. d Changes for period 2005-2010. e Changes for period 2010-2015. f Changes for period 1990-2015. g Changes of averages of economic growth rate (EGR), land consumption rate (LCR) and EGRLCR for sample cities spanning 1990-2015. h Proportions of numbers of cities grouped by different EGRLCR classes spanning 1990-2015. The relief background of map is an ArcGIS online basemap (World Hillshade (WGS84)) obtained from the ArcMap software by Esri (http://goto. arcgisonline.com/maps/Elevation/World_Hillshade). 

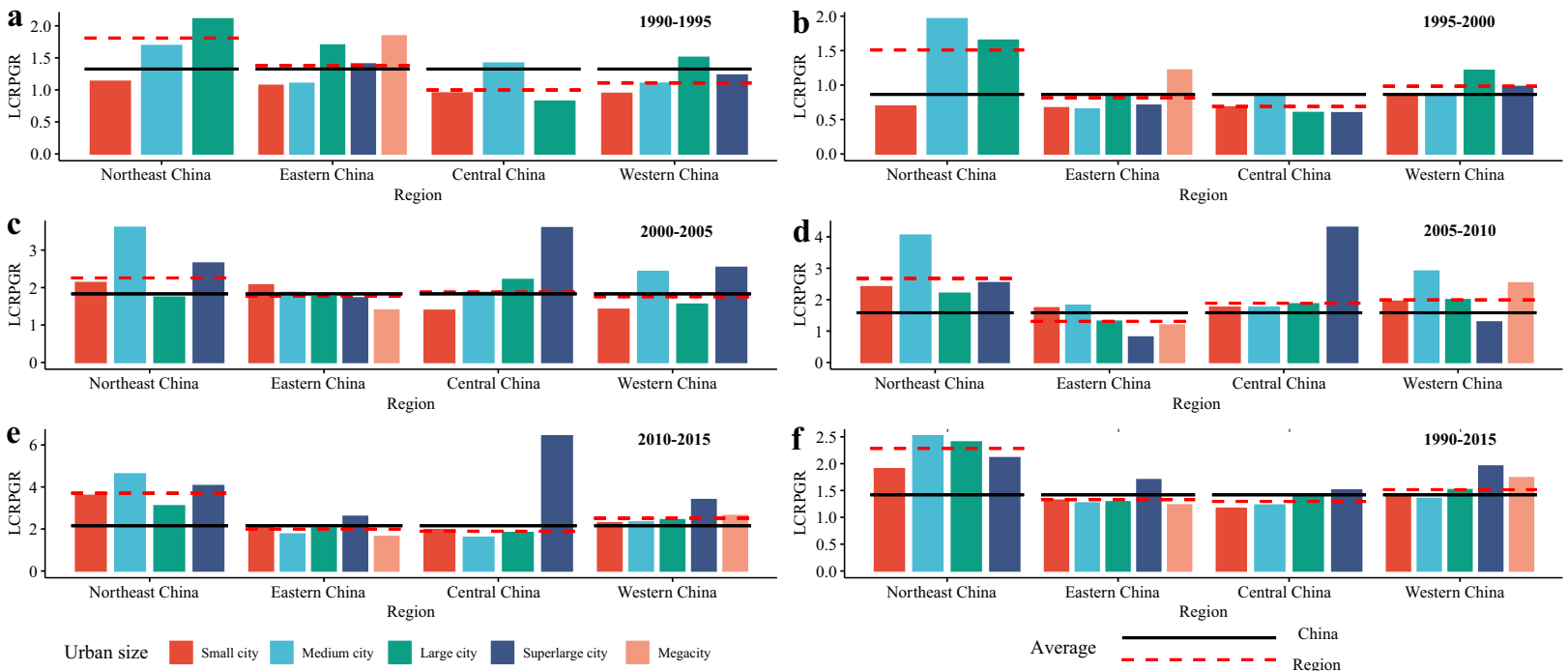

Fig. 3 Changes in ratio of land consumption rate to population growth rate (LCRPGR) of different regions and sizes in China. a Changes for period 1990-1995. b Changes for period 1995-2000. c Changes for period 2000-2005. d Changes for period 2005-2010. e Changes for period 2010-2015. f Changes for period 1990-2015.
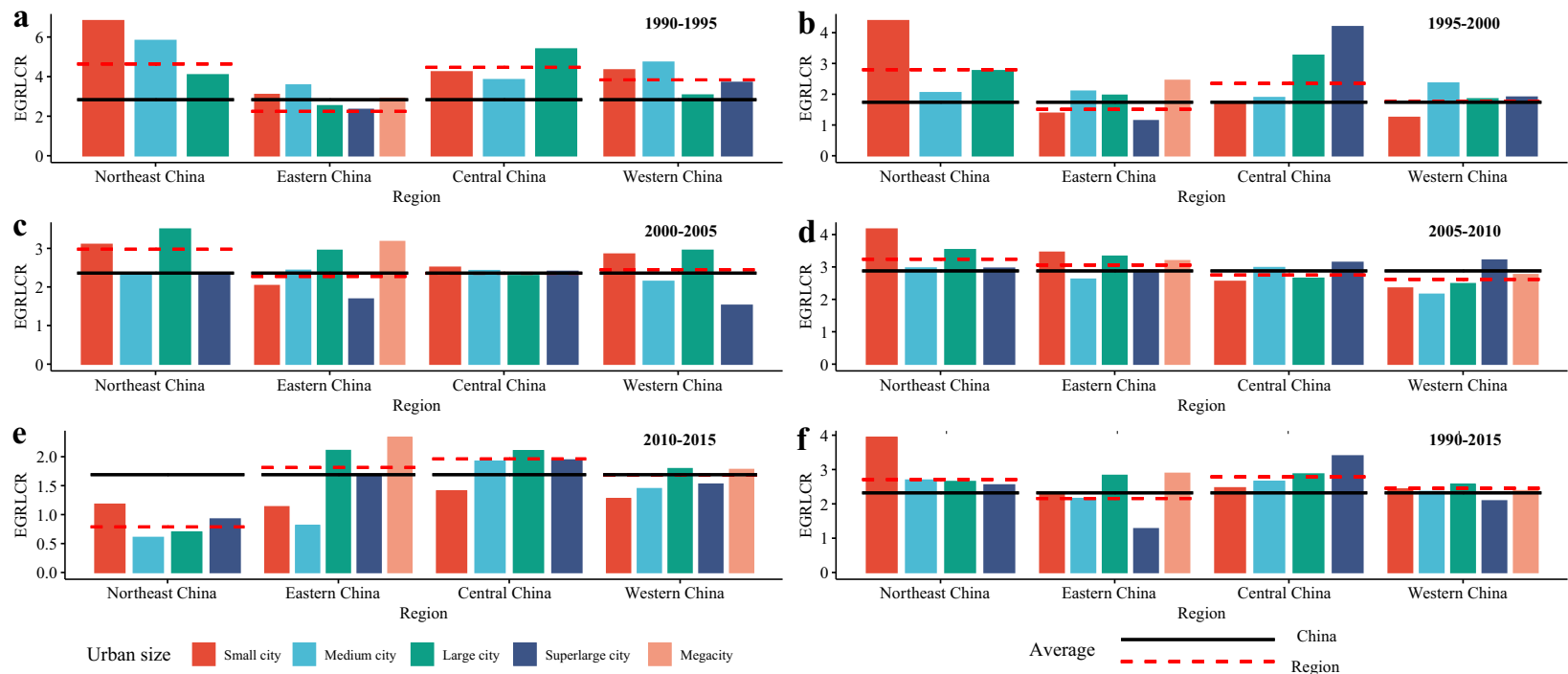

Fig. 4 Changes in ratio of economic growth rate to land consumption rate (EGRLCR) of different regions and sizes in China. a Changes for period 1990-1995. b Changes for period 1995-2000. c Changes for period 2000-2005. d Changes for period 2005-2010. e Changes for period 2010-2015. f Changes for period 1990-2015.

would have to deal with the unbalanced situation between land and population urbanization, and the spatial expansion of superlarge cities in the central region may get out of control.

Figure $4 a-f$ shows the EGRLCR changes in four regions across 313 sample cities of different urban sizes spanning 1990-2015. During the 1990-1995 period, the average of EGRLCR in the northeastern region (4.64) was the highest, followed by central region (4.47), western region (3.83), and eastern region (2.25). During the 2010-2015 period, the average of EGRLCR in all regions hit a low with northeastern region reaching 0.79 , western region reaching 1.68 , eastern region reaching 1.81 , and central region reaching 1.96, respectively. In terms of dynamic change, the EGRLCR changes in all regions experienced a significant downward trend from 1990 to 2015. Moreover, we found that the averages of EGRLCR in the northeastern region remained above those across China throughout the whole evolution except for the 2010-2015 period. On that account, it could be concluded that cities of different urban sizes in
Northeast China may have suffered a more severe economic downturn than other regions during the 2010-2015 period, triggering an imbalance between urban land consumption and economic growth since 2010 .

In this study, we assumed that any urban land identified as built-up area would remain unchanged in the later periods, and employed the postprocessing of overlap to ensure LCR indicator as a positive value. For the cities with a negative value of calculated LCRPGR or EGRLCR, they could be classified into the category where the demographic decline or negative economic growth is simultaneous to spatial expansion. The cities with demographic decline were often located in eastern (Taiwan) and northeastern (Heilongjiang, Jilin, and Liaoning) regions, while the cities with negative economic growth were usually of medium or small population size (e.g., Anshan, Daqing, and Karamay) falling within the category of resource-dependent cities. 

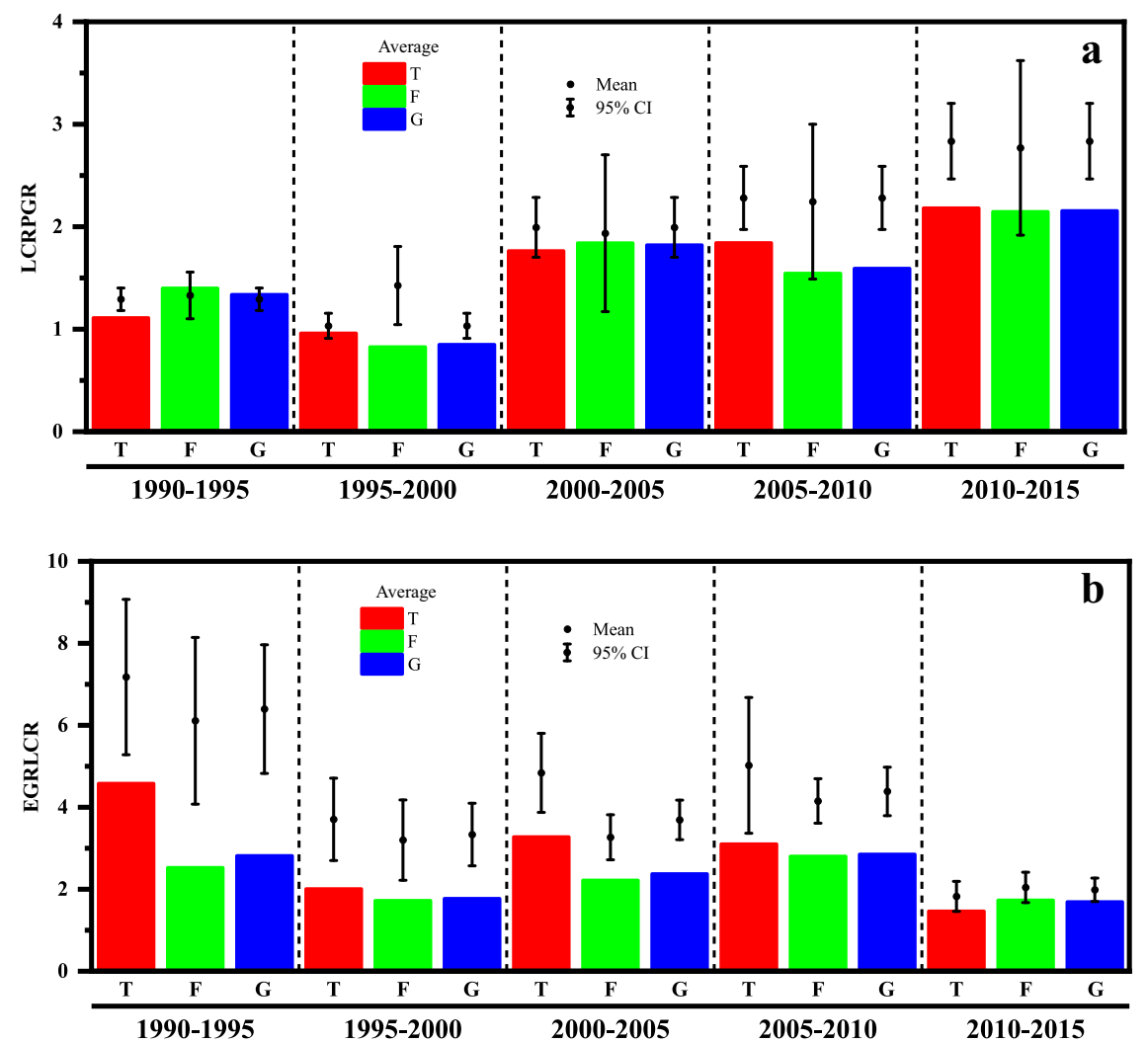

Fig. 5 Changes in land use efficiency indicators of different function types in China. a Changes in ratio of land consumption rate to population growth rate (LCRPGR). b Changes in ratio of economic growth rate to land consumption rate (EGRLCR). $T$ signifies resourcedependent cities; F denotes nonresource-dependent cities; G represents the general level of sample cities in China. Average is the calculated output following the corresponding formulae of land use efficiency indicators based on aggregation of land area, number of persons and Gross Domestic Product (GDP) within the same urban functions. Mean is the sum of all the numbers divided by the total amount of numbers, and $95 \% \mathrm{Cl}$ is the range between the upper and lower $95 \%$ confidence intervals of mean. Among the 433 samples, there are 113 resourcedependent cities and 320 nonresource-dependent cities widely scattering in China.

\section{Urbanization sustainability of different function types}

The LCRPGR change among cities of different urban functions from 1990 to 2015 is shown in Fig. 5a. The average LCRPGR of resource-dependent cities was slightly higher during the 1995-2000, 2005-2010, and 2010-2015 periods than that of nonresource-dependent cities, which was much closer to the general level in China. Although the average LCRPGR of resourcedependent cities expressed a lower value than the national general level during the 1990-1995 period, the LCRPGR change among resource-dependent cities experienced a more apparent upward trend than nonresource-dependent cities throughout the whole evolution. The differences of LCRPGR among cities within resource-dependent and nonresource-dependent categories both tended to get larger. It was not difficult to determine that the resource-dependent cities were facing a challenge for more effective actions of spatial regulation and population migration in the context of high land consumption rate together with low population growth rate.

As shown in Fig. 5b, the EGRLCR change among resourcedependent cities demonstrated a more intense downward trend than that among nonresource-dependent cities. However, the average EGRLCR of resource-dependent cities expressed a lower value than the national general level during the 2010-2015 period, which was contrary to the different situation during other time periods. Besides, the differences of EGRLCR among cities of the same urban functions tended to turn smaller. On that account, the resource-dependent cities were more vulnerable and could be easily influenced by economic downturns in terms of coordination between urban land consumption and economic growth. It is worth noting that the values with $\mathrm{EGRLCR} \leq 0$ were not observed throughout the whole evolution, indicating that the mutual promotion of land urbanization and economic urbanization would have potential to be enhanced ${ }^{38}$.

\section{Urbanization sustainability of different income groups}

The LCRPGR change among cities of different income groups from 1990 to 2015 is shown in Fig. 6a. The average LCRPGR of highincome cities was significantly higher than that of other cities during the 1990-1995, 1995-2000, and 2000-2005 periods, and the gaps among cities of different income groups had narrowed markedly during the 2005-2010 and 2010-2015 periods. After 2000, there were no low-income cities according to the standards of division based on per capital GDP in urban areas. However, the differences among cities within the upper-middle and the lowermiddle-income city groups both turned larger, suggesting that the balance between land and population urbanization for those cities with lower per capital GDP may need a more detailed analysis from other socioeconomic perspectives. It could be concluded that LCR overwhelmed PGR for the high-income cities at the early stages and their compactness was increased over time.

As shown in Fig. $6 \mathrm{~b}$, the average EGRLCR appeared to be inversely proportional to per capital GDP during the 1990-1995 period, but the gaps among cities of different income groups tended to narrow throughout the whole evolution. During the 2010-2015 period, the average EGRLCR of the high, upper-middle and lower-middle-income cities were 1.04, 1.15, and 1.12, respectively, indicating that the land use efficiency among cities of different income groups reached stabilization and 

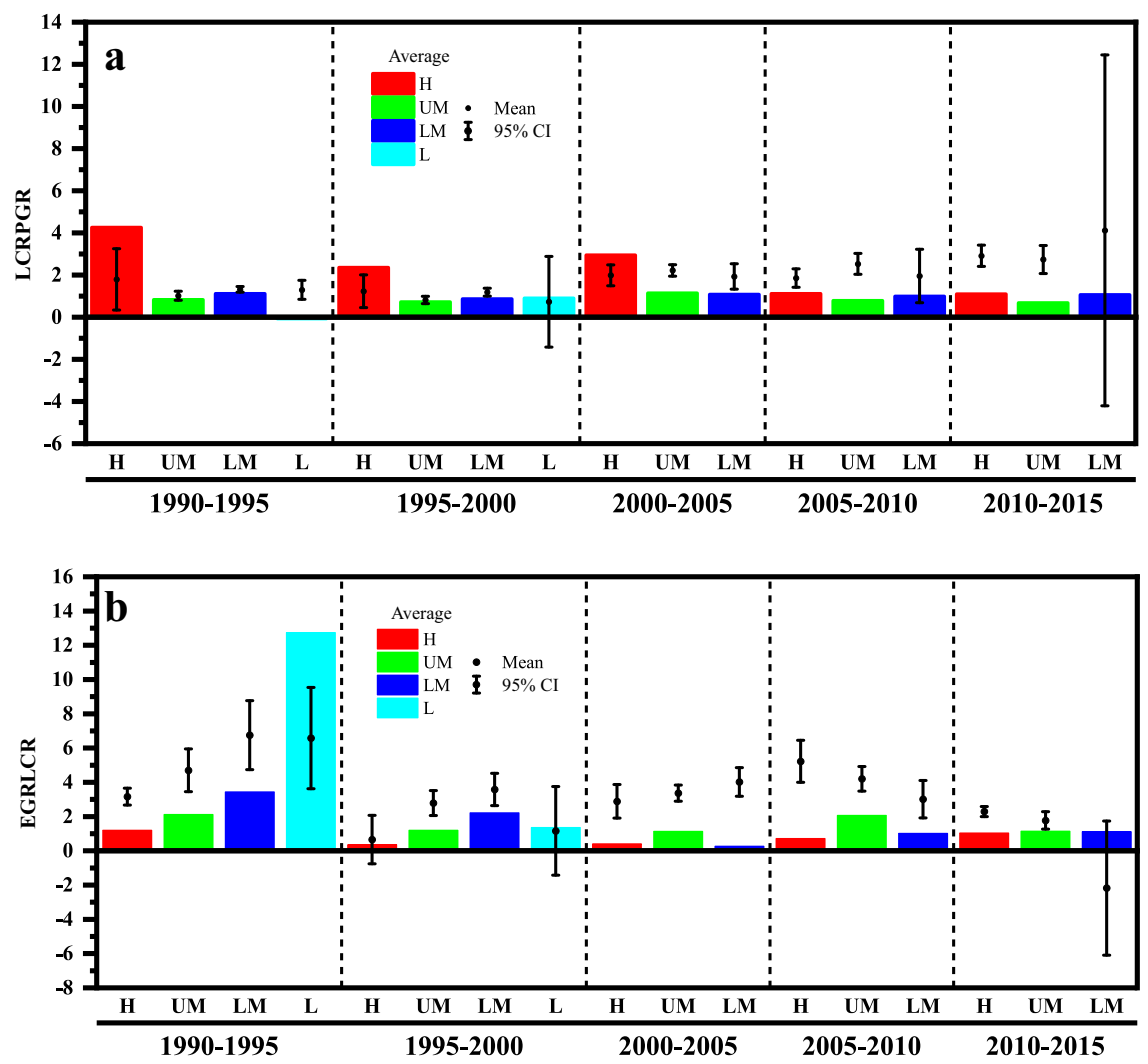

Fig. 6 Changes in land use efficiency indicators of different income groups in China. a Changes in ratio of land consumption rate to population growth rate (LCRPGR). $\mathbf{b}$ Changes in ratio of economic growth rate to land consumption rate (EGRLCR). $H$ signifies high-income cities; UM denotes upper-middle-income cities; LM represents lower-middle-income cities; L stands for low-income cities. Average is the calculated output following the corresponding formulae of land use efficiency indicators based on aggregation of land area, number of persons and GDP within the same income groups. Mean is the sum of all the numbers divided by the total amount of numbers, and $95 \% \mathrm{Cl}$ is the range between the upper and lower $95 \%$ confidence intervals of mean.

homogenization in terms of the economic dimension. In addition, the EGRLCR change of the higher middle and the lower-middleincome cities experienced a more apparent downward trend than the high-income cities spanning 1990-2015. Nonetheless, the evolution of urbanization for cities of different income levels in China is heading toward a more sustainable and coordinated process.

\section{DISCUSSION}

The indicator of LCRPGR measures how compact cities are at any given time and assesses whether they are becoming more or less compact over time. If the value is below one it implies land use with a higher degree of compactness, while a value above one implies land use with a lower degree of compactness. An accepted value of LCRPGR should level off to one, indicating the living density in urban areas is tending towards stability. Similarly, the indicator of EGRLCR measures how productive cities are at any given time and evaluates the production density for cities. Ideally, a higher value implies land use with a better economic performance in terms of per unit GDP. Cities require a reasonable expansion of built-up areas that makes the land use more efficient because they need to plan orderly for future population and economic growth as they expand. If the physical growth of urban areas is disproportionate in relation to population and economic growth, it may lead to decline in land use efficiency with increasing spatial inequalities and lessening of economies of agglomeration included. Land use efficiency as currently formulated is only a measure of change at a macroscopic scale. The indicators of LCRPGR and EGRLCR are scattered dispersedly from the perspective of spatial autocorrelation (Moran's I is insignificant). As an alternative, there are plenty of options for measuring external economic linkages and testing the spatial effects of land use efficiency in urban areas ${ }^{39-41}$, which are mostly issue-specific designed. Our method, albeit not so ideal, could still monitor the spatiotemporal evolution for the sustainability of urbanization using such simple but useful land use efficiency indicators.

According to the UN, the calculation of the LCRPGR indicator requires globally comparable information to analyze the interdependence between urban spatial expansion and corresponding demographic changes. Unfortunately, most of the existing geospatial data cannot be used to estimate LCRPGR because they are not sufficiently harmonized ${ }^{13}$. After converting the urban impervious surface to urban agglomeration area, as per the widely adopted UN recommendations, we acquired comparable information on spatial expansion and urban demographic change using the UN population data together with the derived built-up area product. As mentioned above, we also considered the harmonization between spatial expansion and corresponding economic changes and minimized their discrepancy by integrating the reliable and authoritative data of GDP in the urban areas. This allowed us to identify the relationship between land, population, and economic urbanization using land use efficiency indicators, including LCRPGR and EGRLCR.

These three dimensions of urbanization process are to some extent interactive and indivisible ${ }^{42}$. The imbalance between land and population urbanization is basically accompanied by a corresponding imbalance between land and economic urbanization. For example, resource-dependent cities in the northeastern region showed the highest $L C R P G R$ together with the lowest 
EGRLCR during the 2010-2015 period, indicating that an uncontrolled spatial expansion was accompanied by a stall in population and economic growth. It is worth noting that the calculation of LCR, PGR, and EGR frequently result in outliers for those cities with little change or negative growth, which may hinder the comparison and visualization of indicators among various cities and during different periods. Furthermore, if a statistical mean is used to aggregate the measure for a specific group of cities, the interpretation might be ambiguous and misleading due to the impacts of urban sizes in terms of land, populatio, and economy among various cities. We thus redefined and calculated the aggregation average by following the corresponding formulae of land use efficiency indicators after adding up land area, number of persons and GDP for sample cities within a certain classification scheme.

A global study based on stratified sample of 194 cities around the world shows that East Asia and Oceania had the highest LCRPGR and the developed regions were becoming more densely populated than developing regions ${ }^{12}$. Specifically, the average for developed regions dropped from 2.1 in 1990-2000 to 1.9 in 2000-2015, while the value of developing regions increased from 1.5 in $1990-2000$ to 1.7 in $2000-2015$. As the world saw an overall rise of LCRPGR from 1.68 in 1990-2000 to 1.74 in 2000-2015, meeting SDG Target 11.3 by 2030 required slowing down the decline in compactness. That is, the compactness of cities should be maintained or increased over time ${ }^{43}$. There was much evidence from China ${ }^{9}$, Portugal ${ }^{10}$, and South Africa ${ }^{11}$ corroborating the general pattern, together with more detailed analyses based on circa 10,000 urban samples ${ }^{13,14}$. The information derived in this study could reflect the urbanization trends in cities of different socioeconomic zones, population sizes, function types, and income levels in China, not only creating a baseline for nationwide sustainability assessment but also providing a comparative case for international implementation of Target 11.3.

Compared to other studies with respect to urbanization in China, we complemented the perspective of urban functions and income levels to deeply explore the urbanization pattern. We found that resource-dependent cities in the central and northeastern regions deserved more attention due to their explosive spatial expansion and lasting slowdown in population and economic growth. In the long run, these cities will face severe challenges in terms of balancing between land, population and economic urbanization. In addition, the analysis also highlighted several findings. For example, during the 2010-2015 period, the LCR indicator, a proxy for spatial expansion, showed a slightly increasing trend, which was not consistent with a previous study ${ }^{36}$. It is worth noting that superlarge cities rather than small or medium cities showed the fastest growth trends during the 2010-2015 period, indicating that the spatial expansion of superlarge cities may lose control and should be the focus of strengthened regulations. At the same time, the average LCRPGR of cities in the northeastern region was notably higher than that in other regions, indicating that the policy emphasis should be placed there rather than in the western region. Moreover, the gap of land use efficiency indicators between different income groups has been narrowed between 1990 and 2015, indicating that the evolution of urbanization in China is heading toward a more sustainable and coordinated process.

China's urban land use is closely related to its socioeconomic development. Over the past 25 years, the economic production had, based on 313 samples, grown 2.33 times as much as the built-up areas in urban areas from 1990 to 2015. Meanwhile, the built-up areas experienced a more intense expansion than population growth did, with the average LCRPGR of 1.42. The calculations suggested that cities had been becoming less compact in living density and performed much better in production density. Specific policies towards more efficient land use should be designed and implemented, particularly in terms of

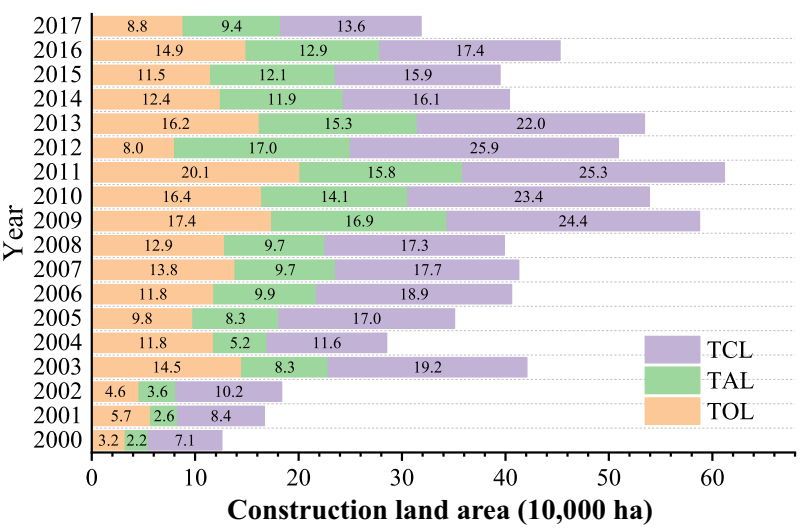

Fig. 7 Changes in the land occupied by construction in Mainland China from 2000 to 2017. TCL transferred cultivated land, TAL transferred noncultivated agricultural land, TOL transferred other nonagricultural land.

strictly controlling transferred construction land use ${ }^{44}$. The new examination and approval of land for construction land between 2000 and 2017 derived from the China Land \& Resources Almanac (1987-2012) and China Land and Resources Statistical Yearbook (2005-2018) is shown in Fig. 7. The cultivated land, noncultivated agricultural land, and other nonagricultural land occupied by construction were on the increase, especially between 2009 and 2013. That is why we observed the peak of average of LCRPGR (2.15) during 2010-2015. Fortunately, the construction land area growth had weakened to below its trend rate after its heyday.

In order to reverse the drastic reduction of agricultural land, the General Land Use Plan and Annual Land Use Plan have been carried out to further ensure the effectiveness of land use management. To date, Chinese government has implemented three General Land Use Plans (1986-2000, 1996-2010, and 2006-2020), whose targets focused on arable land protection and construction land control. To some extent, these policies have alleviated the rampant sprawl of construction land in urban areas, but the efficiency of urban built-up areas in China needs to be further improved ${ }^{45}$. Besides, the urban land use efficiency varies from region to region ${ }^{46}$, even between urban core areas and suburban districts ${ }^{47}$. Because of the regional disparities, formulating specific region-oriented land use planning and promoting coordinated development may be more urgent in the context of disproportionate spatial expansion violating the premise of sustainability by causing adverse environmental consequences.

Governmental planning guidelines for urban development in China dated back to the early 1990s when the policy foci were mainly put on promoting small and medium cities and controlling the size of large cities. Since 2000, China's urban development policies began to emphasize the harmonious development of large, medium, and small cities as well as the development priorities of urban agglomerations. The most recent governmental planning guidelines, such as the National New-Style Urbanization Plan and China's 13th Five-Year Plan, are expected to have major influences on the urbanization progress over the next several years. Until now, the Chinese government has introduced a series of legislation to broadly regulate sustainable development for cities, but their effects are not obvious at the local government level due to the dependency of economic development on land inputs $^{26}$.

To cope with the regional disparities, Chinese government has also developed many macro strategies in support of the sustainable and coordinated transformation, including: China Western Development Plan (1999), Northeast Area Revitalization plan (2004), and Rise of Central China Plan (2016). As mentioned before, we found that the average LCRPGR of superlarge cities in 


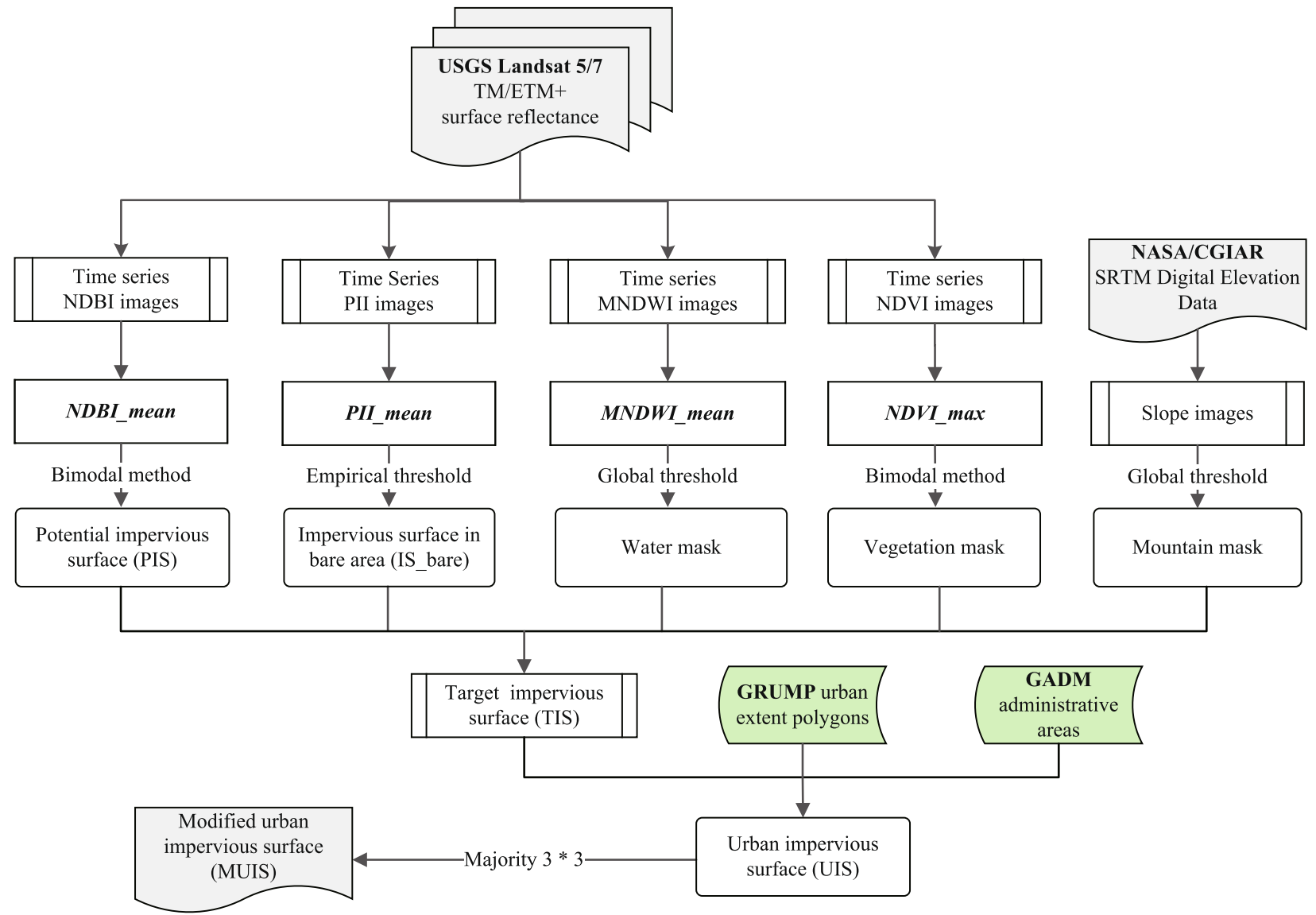

Fig. 8 The flowchart for mapping urban impervious surfaces. NDBI Normalized Difference Building Index, PII Perpendicular Impervious Index, MNDWI Modified Normalized Difference Water Index, NDVI Normalized Difference Vegetation Index.

the central region far exceed the general level, indicating that the impact of the policies on urban expansion was most apparent in the central region ${ }^{48}$. However, regional divergences of urban sustainability were also caused by various regional development policies at different times ${ }^{49}$. For cities in the Northeast China, the trend of land use efficiency indicators showed an abnormal and intense dynamics compared to other regions. A more integrated policy should be implemented to stop the slowdown of economic growth while maintaining a stable population there. Other comprehensive national policies, including ecological protection redlines (EPRs) and major function-oriented zoning (MFZ), have facilitated the land use sustainability based on the principle of ecosystems ${ }^{50,51}$, but the evidence should be supported in combination with more detailed data using different assessment framework rather than SDG 11.

In conclusion, policies have played an important role in shaping urbanization patterns in China during the past several decades ${ }^{52-54}$. To formulate effective regulatory policies, decision-makers should seriously consider differences in cities based on their resources and the environment in which they are located ${ }^{55}$. This decision-making process may lead to the end of ineffective 'one size fits all' policies ${ }^{56}$. Targeted regulations aiming at quality rather than quantity are required to make urban areas more sustainable and turn around the disproportionate development between land, population, and economic urbanization.

\section{METHODS}

\section{Workflow and data}

The method involved three main steps: (1) generation of urban impervious surface and conversion to urban agglomeration area; (2) quantitative measurement of land consumption, population, and economic growth using land use efficiency indicators; (3) assessment of urbanization sustainability in China from multiple perspectives: socioeconomic zones, population sizes, function types, and income groups. Specifically, during the processes of mapping urban impervious surface and calculating land use efficiency indicators, we used four types of data: (1) multisource remote sensing data from Landsat 5/7 TM/ETM+ surface reflectance (1990-2010), Sentinel-1 SAR backscatter (2015), and Sentinel-2 surface reflectance (2015) time series acquired from the Google Earth Engine (GEE) platform; (2) population data derived from the 2018 Revision of World Urbanization Prospects (United Nations, 2018); (3) GDP data derived from the Chinese Urban Statistical Yearbook (1990-2015) and China Statistical Yearbook (1990-2015); (4) auxiliary data such as the Shuttle Radar Topography Mission (SRTM) digital elevation data, urban extent polygons and administrative areas provided by the NASA/CGIAR, the Global RuralUrban Mapping Project, Version 1 (GRUMPv1) ${ }^{57}$, and the Database of Global Administrative Areas, version 3.6 (GADMv3.6), respectively. According to the 2018 revision of World Urbanization Prospects, in China there were 433 county-level or higher cities with 300 thousand inhabitants or more in 2018, and due to data incompleteness, we used a GDP dataset at current prices of only 313 cities in the time range of 1990-2015.

\section{Algorithms to map urban impervious surface}

The flowchart for deriving the 1990-2010 urban impervious surface products is shown in Fig. 8. Time series of the Normalized Difference Building Index (NDBI) ${ }^{58}$, Perpendicular Impervious Index (PII) ${ }^{59}$, Modified Normalized Difference Water Index $(\mathrm{MNDWI})^{60}$, and Normalized Difference Vegetation Index (NDVI) ${ }^{61}$ were derived from the Landsat 5/7 TM/ETM+ surface reflectance time series on the GEE platform. We applied the mean reducer to the time series of NDBI to obtain the yearly average value of NDBI (i.e., NDBI_mean) and then generated the potential impervious surface (PIS) through the bimodal method ${ }^{62}$. To map bare areas, we applied the mean reducer to the time series of PII to obtain the yearly average PII (i.e., PII_mean) and then generated the potential impervious 
Table 1. Accuracy assessment result of urban impervious surface extraction.

\begin{tabular}{llll}
\hline Periods & OA/\% & PA/\% & UA/\% \\
\hline 1990 & 89.95 & 92.36 & 87.10 \\
1995 & 89.25 & 91.80 & 86.20 \\
2000 & 92.88 & 92.77 & 93.00 \\
2005 & 92.58 & 93.03 & 92.05 \\
2010 & 91.53 & 92.92 & 89.90 \\
2015 & 88.03 & 94.50 & 82.22 \\
Average & 91.24 & 92.58 & 89.65 \\
\hline
\end{tabular}

surface in bare areas (i.e., IS_bare) using the empirical threshold. Next, the mean reducer was applied to the time series of MNDWI to obtain the yearly average MNDWI, namely the MNDWI_mean; the maximum composite of NDVI (i.e., NDVI_max) was generated from the time series of NDVI. Masks of water, vegetation, and mountain pixels were obtained by applying thresholds to MNDWI_mean, NDVI_max and slope images, respectively. Then, PIS or IS_bare generated from the Landsat images were utilized to extract the target impervious surface (TIS) after masking water, vegetation and mountains regions. Urban impervious surface (UIS) was delineated explicitly using urban extent polygons and administrative areas. Finally, a modified urban impervious surface (MUIS) was obtained by applying a three-by-three majority filter on the UIS. It should be noted that we adopted a different strategy of parameter configuration for the urban areas with different geographical characteristics by partitioning them into arid and semi-arid, densely vegetated, and common regions. The detailed parametrization for mapping urban impervious surface is shown in Supplementary Table 2.

For the 2015 urban impervious surface products, the basic steps for using the Sentinel-1 SAR scenes and Sentinel-2 surface reflectance images from the GEE platform could be found in Sun et al. ${ }^{63}$. The method demonstrated the effectiveness of fusing optical and SAR data for large area urban land extraction, especially in areas where optical data fail to distinguish urban land from spectrally similar objects.

\section{Validation of urban impervious surface product}

The validation process was carried out based on the visual interpretation of Google Earth images and a uniform interpretation rule was formulated to determine how to judge whether a surface was impervious or pervious. Standard accuracy assessment measures, i.e., overall accuracy (OA), producer's accuracy (PA), and user's accuracy (UA) were computed to assess the extracted accuracy. Since we did not adopt the same methods to map urban impervious surface products during different time periods, the validation process varied slightly. For the 1990-2010 urban impervious surface products, 4000 validation points were randomly generated for each year, with a total of 20,000 for five years $(1990,1995,2000,2005$, and 2010). For the 2015 urban impervious surface products, 224,000 validation points were randomly selected throughout China's major socioeconomic zones ${ }^{63}$. As shown in Table 1, the average OA, PA and UA were $91.24 \%, 92.58 \%$, and $89.65 \%$, respectively. After the process of urban impervious surface mapping, we used the 1990-2015 products to derive the built-up area (i.e., urban agglomeration area).

\section{Conversion from urban impervious surface to built-up area}

Urban agglomeration area (UAA), also known as built-up area, is required for calculating the indicator of land consumption rate ${ }^{43}$. Therefore, the conversion from UIS to UAA is needed when calculating the land use efficiency indicators. Generally, UAA does not relate directly to UIS, and the public spaces considered as part of UAA such as parks or greenbelts cannot be derived from UIS. Besides, the extent of UAA does not overlap with the administrative divisions, and for example, some peri-urban settlements should be considered as part of UAA. On that account, we must delineate urban agglomeration area based on impervious surface by means of spatial data processing. The criteria included:

(1) a minimum urban land size and distance between urban lands. As recommended by the UN, areas of urban land of 20 or more hectares that are less than 200 meters apart should be considered as part of the
Table 2. Classification of cities in China according to population size.

\begin{tabular}{ll}
\hline Categories & Standards of division \\
\hline Megacity & Population size $\geq 10$ million \\
Superlarge city & 5 million $\leq$ population size $<10$ million \\
Large city & 1 million $\leq$ population size $<5$ million \\
Medium city & 500 thousand $\leq$ population size $<1$ million \\
Small city & Population size $<500$ thousand \\
\hline
\end{tabular}

Table 3. Classification of cities in China based on a measure of per capita Gross Domestic Product (GDP).

\begin{tabular}{llc}
\hline Year & Categories & Threshold (Current U.S. dollar) \\
\hline 1990 & Upper middle/high & 7620 \\
1995 & Upper middle/high & 9385 \\
2000 & Upper middle/high & 9265 \\
2005 & Upper middle/high & 10725 \\
2010 & Upper middle/high & 12275 \\
2015 & Upper middle/high & 12475 \\
1990 & Lower middle/upper middle & 2465 \\
1995 & Lower middle/upper middle & 3035 \\
2000 & Lower middle/upper middle & 2995 \\
2005 & Lower middle/upper middle & 3465 \\
2010 & Lower middle/upper middle & 3975 \\
2015 & Lower middle/upper middle & 4035 \\
1990 & Low/lower middle & 610 \\
1995 & Low/lower middle & 765 \\
2000 & Low/lower middle & 755 \\
2005 & Low/lower middle & 875 \\
2010 & Low/lower middle & 1005 \\
2015 & Low/lower middle & 1025 \\
\hline
\end{tabular}

built-up area ${ }^{43}$. With this consideration, we linked all eligible patches of impervious surfaces to form a continuous city proper.

(2) a minimum mapping unit (MMU) of urban land. A rule adopted by the National Geomatics Center of China is that artificial surfaces should occupy more than $8 \times 8$ pixels based on satellite images with a spatial resolution of $30 \times 30 \mathrm{~m}^{64}$. Consequently, any polygon with an area of less than 57600 square meters was eliminated in the vector products derived from urban impervious surface, and holes with areas of less than 57,600 square meters lying inside the main urban areas were filled to maintain the continuous distribution pattern.

(3) the peri-urban impervious areas with close functional relations to be considered as part of the built-up area. Some free-standing rural settlements lay outside the main urban areas, but they may functionally depend on the main urban areas via well-connected roads to provide employment and services. In the process of conversion, we preserved such patches of peri-urban settlements to improve the extent accuracy of built-up area.

(4) the pervious areas used as public spaces to be considered as part of the built-up area. Aided by the Google Earth high-resolution images, we manually supplemented and adjusted patches of parks and greenbelts with artificial structures, and merged the newly-added polygons into the main urban area to generate the built-up area that meets such pre-defined criteria.

Overall, the extraction results delineated a complete boundary of urban impervious surface without loss of spatial details and the conversion results retained the continuous pattern of main urban area distribution that was consistent with the visual interpretation of Google Earth images. As an example, the spatial expansions of urban impervious surface and built-up area compared with Google Earth images in 2015 for Baiyin City 
Table 4. Classification of cities in China by ratio of land consumption rate to population growth rate (LCRPGR) distribution.

Categories

Cities where demographic decline is simultaneous to spatial expansion

LCRPGR $\leq 0$

Cities where population densification takes place

$0<\mathrm{LCRPGR} \leq 1$

Cities where the rate of spatial expansion is greater than the demographic growth

$1<\mathrm{LCRPGR} \leq 2$

Cities where spatial expansion takes place at a pace that is at least double the one of demographic growth

LCRPGR $>2$

Table 5. Classification of cities in China by ratio of economic growth rate to land consumption rate (EGRLCR) distribution.

Categories

Standards of division

Cities where zero or negative economic growth is simultaneous to spatial expansion

EGRLCR $\leq 0$

Cities where economic growth rate is lower than spatial expansion

$0<\mathrm{EGRLCR} \leq 1$

Cities where economic growth rate is greater than spatial expansion

$1<\mathrm{EGRLCR} \leq 2$

Cities where economic growth takes place at a pace that is at least double but lower than quadruple the one

of spatial expansion

Cities where economic growth takes place at a pace that is at least quadruple the one of spatial expansion

$2<\mathrm{EGRLCR} \leq 4$

$\mathrm{EGRLCR}>4$

(Gansu Province), Hefei City (Anhui Province), and Shanghai City are shown in Supplementary Fig. 1.

\section{Modified land use efficiency indicators}

In this study, we used SDG 11.3.1 (i.e., LCRPGR) to measure the relationship between urban land consumption and population growth. The methodology for SDG 11.3.1 is established and referenced in the SDG indicator Metadata Repository (https://unstats.un.org/sdgs/metadata). The LCRPGR is computed as follows:

LCRPGR $=\frac{\mathrm{LCR}}{\mathrm{PGR}}=\frac{\mathrm{LN}\left(\mathrm{Urb}_{t+n} / \mathrm{Urb}_{t}\right)}{\mathrm{LN}\left(\mathrm{Pop}_{t+n} / \mathrm{Pop}_{t}\right)}$

where $U r b_{t}$ and $U r b_{t+n}$ are the total areal extent of the land consumed (extent of the urban agglomeration area, which is quantified as built-up area) at the initial reference year $t$, and at the final reference year $t+n$, respectively; $P_{o p_{t}}$ and $P_{o p_{t+n}}$ are the total population of the specific spatial unit at the initial reference year $t$, and at the final reference year $t+n$, respectively; and $L N$ refers to the natural logarithm of the ratio.

SDG 11.3.1 captures the demographic pressure of urban expansion but partially excludes the economic dimension. In this study, we proposed a supplementary indicator to measure the relationship between urban land consumption and economic growth, which is the ratio of economic growth rate to land consumption rate, namely EGRLCR. The ratio could be summarized as:

$\mathrm{EGRLCR}=\frac{\mathrm{ECR}}{\mathrm{LCR}}=\frac{\mathrm{LN}\left(\mathrm{GDP}_{t+n} / \mathrm{GDP}_{t}\right)}{\mathrm{LN}\left(\mathrm{Urb}_{t+n} / \mathrm{Urb}_{t}\right)}$

where $G D P_{t}$ and $G D P_{t+n}$ are the total amount of GDP within a certain spatial unit at the initial reference year $t$, and at the final reference year $t+n$, respectively.

Both in the calculation of LCRPGR and EGRLCR, the periods for both land consumption, population, and economic growth rates should be comparable. Here we used LCRPGR together with EGRLCR to estimate the land use efficiency because of urban expansion pressure from demographic and economic perspectives. For the accurate calculation of area, we used a transverse Mercator map projection, and in order to minimize the deformation, we accordingly divided China into zones six degrees wide.

\section{Assessment of urbanization sustainability in China}

The 433 county-level or higher cities in China could be classified into diverse categories in terms of socioeconomic zones, population sizes and function types. Here we assigned the sample cities to one of four recognized socioeconomic zones, namely Eastern China, Central China, Western China, and Northeast China. According to the China's State Council $^{65}$, we divided them into five categories based on the resident population scale of urban areas (Table 2). As the resource-dependent cities accounted for a relatively large proportion of the 433 cities and their sustainable development are an important area of research on regional industrial development and urban sustainability, we partitioned them to better distinguish the differences between resource-dependent cities and other nonresource-dependent cities, whose distribution was retrieved from Fan et al. ${ }^{66}$. In order to contextualize the evolution of Chinese urbanization in an international classification scheme, we also split the 313 sample cities with complete time series into four income groups, including high, uppermiddle, lower-middle, and low-income cities based on a measure of per capita GDP (Table 3), which was first introduced by the World Bank's World Development Report in 1978 and has been adjusted for prices over time. For details, the official exchange rates of China Yuan relative to the U.S. dollar in the time range of 1990-2015 are shown in Supplementary Table 1.

Moreover, we clustered the sample cities into four classes based on LCRPGR (Table 4) and reclassified them into five categories based on EGRLCR (Table 5) to quantitatively determine the relationship between land consumption, population and economic growth. The comparisons on LCRPGR and EGRLCR changes among socioeconomic zones, population sizes, function types, together with different levels of per capital GDP could shed a light on differences in urbanization patterns in China over 25 years, which may contribute to decision and policy-making in a spatially explicit manner.

\section{Reporting summary}

Further information on research design is available in the Nature Research Reporting Summary linked to this article.

\section{DATA AVAILABILITY}

The data generated and analyzed during this study are described in the following data record: https://doi.org/10.6084/m9.figshare.1429916367. The datasets used in this study, including multisource remote sensing imagery, auxiliary geospatial data, population, construction land, and GDP statistics, were all obtained from publicly available data with free accesses. Available remote sensing data include Landsat 5/7 TM/ETM + surface reflectance (https://earthexplorer.usgs.gov/), Sentinel-1 SAR backscatter and Sentinel-2 surface reflectance (https://scihub.copernicus.eu/). Available geospatial data include digital elevation from SRTM (https://www2.jpl.nasa.gov/srtm/), urban extent polygons from GRUMPV1 (http://sedac.ciesin.columbia.edu/) and administrative areas from GADMv3.6 (http://www.gadm.org/). UN's World Urbanization Prospects 2018 is available at https://population.un.org/wup/. The satellitederived high-resolution urban impervious surface maps and the urban built-up area products will be freely and publicly available at https://doi.org/10.11922/sciencedb j00076.00004. The official exchange rates of China Yuan relative to the U.S. dollar is available at https://data.worldbank.org/indicator/PA.NUS.FCRF. The construction land and GDP data of cities in China were searched and acquired at https://data.cnki.net/ Yearbook. Other data, which were derived from the original datasets but not aforementioned, are elaborately illustrated in the part of Supplementary Information. 


\section{CODE AVAILABILITY}

The JavaScript scripts used for preprocessing the Landsat and Sentinel time series data in the Google Earth Engine platform and the Python script for generating urban built-up area products based on urban impervious surface maps using ArcGIS Desktop 10.7 software are all available on reasonable request from H.J. or Z.S.

Received: 17 August 2020; Accepted: 2 May 2021; Published online: 05 July 2021

\section{REFERENCES}

1. UN. Transforming our World: The 2030 Agenda for Sustainable Development A/RES/ 70/1. https://undocs.org/en/A/RES/70/1 (2015).

2. Acuto, M., Parnell, S. \& Seto, K. C. Building a global urban science. Nat. Sustain. 1, 2-4 (2018).

3. UN DESA. Global Sustainable Development Report 2019. https://sustainabledev elopment.un.org/content/documents/24797GSDR_report_2019.pdf (2019).

4. Anderson, K., Ryan, B., Sonntag, W., Kavvada, A. \& Friedl, L. Earth observation in service of the 2030 Agenda for Sustainable Development. Geo Spatial Inf. Sci. 20, 77-96 (2017).

5. Andries, A. et al. Translation of Earth observation data into sustainable development indicators: an analytical framework. Sustain. Dev. 27, 366-376 (2019).

6. Melchiorri, M. et al. Unveiling 25 years of planetary urbanization with remote sensing: perspectives from the global human settlement layer. Remote Sens. 10, 768 (2018).

7. Liu, X. et al. High-resolution multi-temporal mapping of global urban land using Landsat images based on the Google Earth Engine Platform. Remote Sens. Environ. 209, 227-239 (2018).

8. Gong, P. et al. Annual maps of global artificial impervious area (GAIA) between 1985 and 2018. Remote Sens. Environ. 236, 111510 (2020).

9. Wang, Y., Huang, C., Feng, Y., Zhao, M. \& Gu, J. Using Earth observation for monitoring SDG 11.3. 1-ratio of land consumption rate to population growth rate in Mainland China. Remote Sens. 12, 357 (2020).

10. Nicolau, R., David, J., Caetano, M. \& Pereira, J. Ratio of land consumption rate to population growth rate-analysis of different formulations applied to mainland Portugal. ISPRS Int. J. Geo Inf. 8, 10 (2019).

11. Mudau, N. et al. Assessment of SDG indicator 11.3. 1 and urban growth trends of major and small cities in South Africa. Sustainability 12, 7063 (2020).

12. UN DESA. The Sustainable Development Goals Report 2016. https://unstats.un.org/ sdgs/report/2016/The\%20Sustainable\%20Development\%20Goals\%20Report\% 202016.pdf (2016)

13. Melchiorri, M., Pesaresi, M., Florczyk, A. J., Corbane, C. \& Kemper, T. Principles and applications of the global human settlement layer as baseline for the land use efficiency indicator-SDG 11.3. 1. ISPRS Int. J. Geo Inf. 8, 96 (2019).

14. Schiavina, M. et al. Multi-scale estimation of land use efficiency (SDG 11.3. 1) across 25 years using global open and free data. Sustainability 11, 5674 (2019).

15. Buettner, T. Urban estimates and projections at the United Nations: the strengths, weaknesses, and underpinnings of the world urbanization prospects. Spatial Demogr. 3, 91-108 (2015).

16. Gallego, F. J., Batista, F., Rocha, C. \& Mubareka, S. Disaggregating population density of the European Union with CORINE land cover. Int. J. Geogr. Inf. Sci. 25, 2051-2069 (2011)

17. Seto, K. C. \& Fragkias, M. Quantifying spatiotemporal patterns of urban land-use change in four cities of China with time series landscape metrics. Landscape Ecol. 20, 871-888 (2005).

18. Weng, Q. Land use change analysis in the Zhujiang Delta of China using satellite remote sensing, GIS and stochastic modelling. J. Environ. Manag. 64, 273-284 (2002).

19. Yang, C. et al. Spatiotemporal evolution of urban agglomerations in four major bay areas of US, China and Japan from 1987 to 2017: evidence from remote sensing images. Sci. Total Environ. 671, 232-247 (2019).

20. Barrington-Leigh, C. \& Millard-Ball, A. A century of sprawl in the United States. Proc. Natl Acad. Sci. USA 112, 8244-8249 (2015).

21. Bounoua, L., Nigro, J., Zhang, P., Thome, K. \& Lachir, A. Mapping urbanization in the United States from 2001 to 2011. Appl. Geogr. 90, 123-133 (2018).

22. Gong, P., Li, X. \& Zhang, W. 40-Year (1978-2017) human settlement changes in China reflected by impervious surfaces from satellite remote sensing. Sci. Bull. 64, 756-763 (2019).

23. Güneralp, B., Reba, M., Hales, B. U., Wentz, E. A. \& Seto, K. C. Trends in urban land expansion, density, and land transitions from 1970 to 2010: a global synthesis. Environ. Res. Lett. 15, 044015 (2020).

24. Liu, X. et al. High-spatiotemporal-resolution mapping of global urban change from 1985 to 2015. Nat. Sustain. 3, 564-570 (2020).
25. Feng, Y., Wang, X., Du, W., Liu, J. \& Li, Y. Spatiotemporal characteristics and driving forces of urban sprawl in China during 2003-2017. J. Clean Prod. 241, 118061 (2019).

26. Li, G. \& Li, F. Urban sprawl in China: differences and socioeconomic drivers. Sci. Total Environ. 673, 367-377 (2019).

27. Li, G., Sun, S. \& Fang, C. The varying driving forces of urban expansion in China: Insights from a spatial-temporal analysis. Landsc. Urban Plan. 174, 63-77 (2018).

28. Wang, J., Qu, S., Peng, K. \& Feng, Y. Quantifying urban sprawl and its driving forces in China. Discrete Dyn. Nat. Soc. 2019, 1-14 (2019).

29. Bai, X., Chen, J. \& Shi, P. Landscape urbanization and economic growth in China: positive feedbacks and sustainability dilemmas. Environ. Sci. Technol. 46, 132-139 (2012).

30. Seto, K. C. \& Kaufmann, R. K. Modeling the drivers of urban land use change in the Pearl River Delta, China: integrating remote sensing with socioeconomic data. Land Econ. 79, 106-121 (2003).

31. Bai, X., Shi, P. \& Liu, Y. Realizing China's urban dream. Nature 509, 158-160 (2014).

32. Zhang, S., Lv, Y., Yuan, J., He, G. \& Zheng, X. Roles of sustainable urbanization in promoting the implementation of UN Sustainable Development Goals in China. Acta Ecol. Sin. 39, 1135-1143 (2019).

33. UN DESA. World Urbanization Prospects: The 2018 Revision. https://population.un. org/wup/Publications/Files/WUP2018-Report.pdf (2018).

34. Sun, Z. et al. Assessing 40 years of spatial dynamics and patterns in megacities along the Belt and Road region using satellite imagery. Int. J. Digital Earth 14, 71-87 (2021).

35. Gao, B., Huang, Q., He, C., Sun, Z. \& Zhang, D. How does sprawl differ across cities in China? A multi-scale investigation using nighttime light and census data. Landsc. Urban Plan. 148, 89-98 (2016).

36. Liu, Z., Liu, S., Qi, W. \& Jin, H. Urban sprawl among Chinese cities of different population sizes. Habitat Int. 79, 89-98 (2018).

37. Zhang, M., Tan, F. \& Lu, Z. Resource-based cities (RBC): a road to sustainability. Int. J. Sustain. Dev. World Ecol. 21, 465-470 (2014).

38. Bai, X., Chen, J. \& Shi, P. Landscape urbanization and economic growth in China: positive feedbacks and sustainability dilemmas. Environ. Sci. Technol. 46, 132-139 (2011).

39. Huang, Z., He, C. \& Zhu, S. Do China's economic development zones improve land use efficiency? The effects of selection, factor accumulation and agglomeration. Landsc. Urban Plan. 162, 145-156 (2017).

40. Gao, X., Zhang, A. \& Sun, Z. How regional economic integration influence on urban land use efficiency? A case study of Wuhan metropolitan area, China. Land Use Policy 90, 104329 (2020).

41. Pan, H., Yang, T., Jin, Y., Dall'Erba, S. \& Hewings, G. Understanding heterogeneous spatial production externalities as a missing link between land-use planning and urban economic futures. Reg. Studies 55, 90-100 (2020).

42. Weng, Q. \& Yang, S. An approach to evaluation of sustainability for Guangzhou's urban ecosystem. Int. J. Sustain. Dev. World Ecol. 10, 69-81 (2003).

43. UN Habitat. SDG Goal 11 Monitoring Framework: A guide to assist national and local governments to monitor and report on SDG goal 11 indicators. https://www. local2030.org/library/60/SDG-Goal-11-Monitoring-Framework-A-guide-to-assistnational-and-local-governments-to-monitor-and-report-on-SDG-goal-11-indicat ors.pdf (2019).

44. Ma, L., Long, H., Tu, S., Zhang, Y. \& Zheng, Y. Farmland transition in China and its policy implications. Land Use Policy 92, 104470 (2020).

45. Chen, Y., Chen, Z., Xu, G. \& Tian, Z. Built-up land efficiency in urban China: insights from the general land use plan (2006-2020). Habitat Int. 51, 31-38 (2016).

46. Liu, Y., Zhang, Z. \& Zhou, Y. Efficiency of construction land allocation in China: an econometric analysis of panel data. Land Use policy 74, 261-272 (2018).

47. You, L., Li, Y., Wang, R. \& Pan, H. A benefit evaluation model for build-up land use in megacity suburban districts. Land Use Policy 99, 104861 (2020).

48. Kuang, W. 70 years of urban expansion across China: trajectory, pattern, and national policies. Sci. Bull. 65, 1970-1974 (2020).

49. Kuang, W. National urban land-use/cover change since the beginning of the 21 st century and its policy implications in China. Land Use Policy 97, 104747 (2020).

50. Jiang, B., Bai, Y., Wong, C. P., Xu, X. \& Alatalo, J. M. China's ecological civilization program-implementing ecological redline policy. Land Use Policy 81, 111-114 (2019).

51. Fan, J. et al. Reshaping the sustainable geographical pattern: a major function zoning model and its applications in China. Earth Future 7, 25-42 (2019).

52. Liu, J. et al. Spatiotemporal characteristics, patterns, and causes of land-use changes in China since the late 1980s. J. Geogr. Sci. 24, 195-210 (2014).

53. Liu, Y., Fang, F. \& Li, Y. Key issues of land use in China and implications for policy making. Land Use Policy 40, 6-12 (2014).

54. Wu, J., Xiang, W.-N. \& Zhao, J. Urban ecology in China: historical developments and future directions. Landsc. Urban Plan. 125, 222-233 (2014).

55. Huang, X., Xia, J., Xiao, R. \& He, T. Urban expansion patterns of 291 Chinese cities, 1990-2015. Int. J. Digital Earth 12, 62-77 (2019). 
56. Fang, C., Li, G. \& Wang, S. Changing and differentiated urban landscape in China: spatiotemporal patterns and driving forces. Environ. Sci. Technol. 50, 2217-2227 (2016).

57. Balk, D. L. et al. Determining global population distribution: methods, applications and data. Adv. Parasitol. 62, 119-156 (2006).

58. Zhang, Y., Odeh, I. O. \& Han, C. Bi-temporal characterization of land surface temperature in relation to impervious surface area, NDVI and NDBI, using a subpixel image analysis. Int. J. Appl. Earth Obs. Geoinf. 11, 256-264 (2009).

59. Tian, Y., Xu, Y. \& Yang, X. Perpendicular impervious index for remote sensing of multiple impervious surface extraction in cities. Acta Geodaet. Cartograph. Sin. $\mathbf{4 6}$, 468 (2017).

60. Xu, H. A study on information extraction of water body with the modified normalized difference water index (MNDWI). J. Remote Sens. 9, 589-595 (2005).

61. Chen, J. et al. A simple method for reconstructing a high-quality NDVI time-series data set based on the Savitzky-Golay filter. Remote Sens. Environ. 91, 332-344 (2004)

62. Kapur, J. N., Sahoo, P. K. \& Wong, A. K. A new method for gray-level picture thresholding using the entropy of the histogram. Comput. Vision Graphics image Process. 29, 273-285 (1985).

63. Sun, Z., Xu, R., Du, W., Wang, L. \& Lu, D. High-resolution urban land mapping in China from sentinel 1A/2 imagery based on Google Earth Engine. Remote Sens. 11, 752 (2019).

64. Chen, J. et al. Global land cover mapping at $30 \mathrm{~m}$ resolution: a POK-based operational approach. ISPRS J. Photogramm. Remote Sens. 103, 7-27 (2015).

65. China's State Council. Notice on the adjustment of standards for the division of urban scale. http://www.gov.cn/zhengce/content/2014-11/20/content_9225.htm (2014).

66. Fan, J., Sun, W. \& Fu, X. Problems, reasons and strategies for sustainable development of mining cities in China. J. Natural Resources 20, 68-77 (2005).

67. Jiang, $\mathrm{H}$. et al. Data record for the article: an assessment of urbanization sustainability in China between 1990 and 2015 Using Land Use Efficiency Indicators. Figshare https://doi.org/10.6084/m9.figshare.14299163 (2021).

\section{ACKNOWLEDGEMENTS}

The research was funded by the Strategic Priority Research Program of the Chinese Academy of Sciences (grant no. XDA19030104; XDA19090121) and the Key R\&D Program Projects in Hainan Province (grant no. ZDYF2020192). We thank many students (including X.Z. and B.F.) for their hard work with validating our urban impervious surface products and conducting the conversion to urban agglomeration area. We are also grateful for Y.H. and Y.M. who have provided assistance to improve the paper.

\section{AUTHOR CONTRIBUTIONS}

Z.S., H.J., H.G., and Q.W. designed the research; W.D. and H.J. contributed the data with support from Z.S., Q.X., and G.C.; H.J. performed data analysis and interpreted the results; H.J. and Z.S. wrote the draft with contributions from H.G. and Q.W. All authors reviewed and commented on the manuscript.

\section{COMPETING INTERESTS}

The authors declare no competing interests.

\section{ADDITIONAL INFORMATION}

Supplementary information The online version contains supplementary materia available at https://doi.org/10.1038/s42949-021-00032-y.

Correspondence and requests for materials should be addressed to H.G. or Q.W.

Reprints and permission information is available at http://www.nature.com/ reprints

Publisher's note Springer Nature remains neutral with regard to jurisdictional claims in published maps and institutional affiliations.

(C) Open Access This article is licensed under a Creative Commons Attribution 4.0 International License, which permits use, sharing, adaptation, distribution and reproduction in any medium or format, as long as you give appropriate credit to the original author(s) and the source, provide a link to the Creative Commons license, and indicate if changes were made. The images or other third party material in this article are included in the article's Creative Commons license, unless indicated otherwise in a credit line to the material. If material is not included in the article's Creative Commons license and your intended use is not permitted by statutory regulation or exceeds the permitted use, you will need to obtain permission directly from the copyright holder. To view a copy of this license, visit http://creativecommons. org/licenses/by/4.0/.

(c) The Author(s) 2021 